\title{
PENERAPAN PEMBELAJARAN TUGAS INDIVIDU TERHADAP KEMAMPUAN BELAJAR MANDIRI PADA MAHASISWA BARU
}

\author{
Achmadi \\ PG - PAUD FKIP Universitas PGRI Adi Buana Surabaya \\ email: ajisyauqi04@yahoo.com \\ Made Ayu Anggreni \\ PAUD FKIP Universitas PGRI Adi Buana Surabaya
}

\begin{abstract}
Abstrak
Mahasiswa baru (khususnya di tahun pertama dan kedua) dalam mengikuti perkuliahan masih cenderung mengikuti pola pembelajaran di SLTA. Selama proses perkuliahan berlangsung mahasiswa hanya aktif mendengarkan saja. Tidak banyak terlibat berinteraksi timbal balik antara dosen - mahasiswa atau mahasiswa - mahasiswa. Hanya sekitar $10 \%$ bahkan kurang dari jumlah itu, mahasiswa yang mau bertanya dan berinteraksi terhadap perkuliahan dari dosen. Tentu saja bila interaksi timbal balik tidak optimal maka proses dan hasil pembelajarannyapun dikategorikan kurang maksimal. Bila dicermati faktor penyebabnya antara lain mahasiswa: 1). Belum biasa bertanya, karena maindset belajar belum berubah, masih menggunakan maindset belajar di SLTA. 2). Cara belajar di perguruan tinggi belum terbentuk. 3) Masih ada rasa malu, bahkan rasa takut atau minder akan pertanyaan yang dimunculkan dikategorikan tidak ilmiah. 4). Bila merespon pertanyaan dosen dilakukan mahasiswa secara bersamaan sehingga suaranya terdengar kurang jelas. Bila disuruh menjawab sendirian malah diam atau tidak mau merespon. 5). Bila ada yang mau berinteraksi dengan dosen hanya mahasiswa tertentu saja. Bertolak dari fakta tersebut, maka yang akan dikaji dan diteliti adalah menumbuhkan kemandirian belajar bagi mahasiswa baru melalui pembelajaran tugas individu. Tujuan penelitian ini agar mahasiswa memiliki mindset cara belajar di Perguruan Tinggi yakni aktif belajar secara mandiri. Adapun metode penelitian yang digunakan adalah pre eksperimen one group design dengan analisa uji t.
\end{abstract}

Kata kunci: Tugas individu, Belajar mandiri. 


\section{LATAR BELAKANG}

Mahasiswa baru (khususnya di tahun pertama dan kedua) dalam mengikuti perkuliahan masih cenderung mengikuti pola pembelajaran di SLTA. Maindset belajar pola perguruan tinggi belum terbentuk. Selama proses perkuliahan berlangsung mahasiswa hanya aktif mendengarkan saja, aktif menerima materi dari dosen saja. Tidak banyak terlibat untuk bertanya, mengekplore materi perkuliahan, dan bahkan untuk menjawab pertanyaan dari dosen-pun tidak pernah terjadi. Bila ada mahasiswa yang terlibat dan berinteraksi timbal balik antara dosen - mahasiswa atau mahasiswa mahasiswa prosentasenya sangat kecil. Tentu saja bila interaksi timbal balik tidak optimal maka proses dan hasil pembelajaran dikategorikan sangat rendah. Penelitian ini perlu dilakukan karena fakta di lapangan menunjukkan bahwa banyak mahasiswa baru kurang aktif dan kurang komunikatif dalam mengikuti proses perkuliahan. Hal ini dikarenakan antara lain: 1). Belum terbiasa bertanya, karena maindset belajar belum berubah, masih menggunakan maindset belajar di SLTA. 2). Cara belajar di perguruan tinggi belum terbentuk pada diri mahasiswa. 3) Mereka tidak mau berinteraksi karena ada rasa malu, dan rasa minder akan pertanyaan yang dimunculkannya. Mereka takut materi pertanyaannya dikategorikan tidak ilmiah. 4). Memang secara riil mereka tidak biasa bertanya atau merespon suatu pertanyaan. Bila ada yang mau berinteraksi saat perkuliahan berlangsung hanya mahasiswa tertentu saja. Bertolak dari fakta tersebut diatas, maka yang akan dikaji dan diteliti adalah menumbuhkan sikap kemandirian dalam belajar bagi mahasiswa baru melalui pemberian tugas individu. Bentuknya adalah pembelajaran yang menekankan kepada proses keterlibatan masingmasing individu dalam kegiatan perkuliahan. Jadi setiap mahasiswa dalam menyelesaikan perkuliahan harus dapat belajar secara mandiri. Adapun indikator belajar mandiri adalah: mencari materi/referensi sendiri, berupaya secara mandiri dalam memahami materi, serta mempertahankan dan mengklarifikasi materi secara mandiri pada saat 
berdiskusi dengan teman-teman perkuliahannya. Tujuan penelitian ini agar mahasiswa baru (semester 1 dan 2) memiliki mindset cara belajar di Perguruan Tinggi yakni aktif belajar secara mandiri. Adapun metode penelitian yang digunakan adalah pre eksperimen one group design. Metode pengumpul data yang digunakan adalah observasi, dan analisis datanya dengan statistik uji t. Kesimpulan dari hasil penelitian ini adalah penerapan pembelajaran tugas individu sangat efektif terhadap kemampuan belajar mandiri di Perguruan Tinggi.

\section{METODE PENELITIAN}

Jenis penelitian yang digunakan dalam penelitian ini adalah metode pre-eksperimental yaitu pre test post test one group design, dalam menerapkan pembelajaran tugas individu terhadap kemampuan belajar secara mandiri bagi mahasiwa PG-PAUD Universitas PGRI Adi Buana Surabaya. Sedangkan rancangan penelitiannya mengetrapkan treatment by subyek yaitu menganalisa perbedaan dalam satu group sampel, atau untuk menguji efektivitas pemberian tugas individual dalam perkuliahan pada satu group sampel. Secara skematis penelitian ini dapat digambarkan sebagai berikut:

$$
O_{1}-X-O_{2}
$$

Keterangan:

$\mathrm{O} 1=$ Pre test. dilakukan dengan cara mengobservasi terhadap perilaku mahasiswa melakukan tugas individual pada saat perkuliahan. Kegiatan ini dilakukan sebelum/awal eksperimen atau pemberian tindakan.

$\mathrm{X}=$ Perlakuan (pengetrapan pemberian tugas individu dalam perkuliahan yaitu: mencari, memahami, dan mempresentasikan tugas secara mandiri).

$\mathrm{O} 2=$ Post test dilakukan dengan cara mengobservasi terhadap perilaku mahasiswa setelah mengikuti dan melaksanakan tugas-tugas individu dalam perkuliahan. 
Lokasi Penelitiannya adalah

mahasiswa PG-PAUD tahun

akademik

Universitas

FKIP

Buana

Surabaya sebanyak 20 orang.

Sedangkan metode pengumpul data yang digunakan adalah observasi untuk mengamati perilaku mahasiswa dalam menyelesaikan tugas perkuliahan secara individual. Tujuannya untuk memperoleh data

tentang perilaku keaktifan mahasiswa dalam: mencari materi/referensi perkuliahan sendiri, berupaya untuk memahami materi secara mandiri, serta mempertahankan dan mengklarifikasi materi secara mandiri saat berdiskusi dengan temantemannya.

Adapun instrumen observasi dan rubrik penilaiannya sebagai berikut:

\section{Instrumen observasi dan rubrik penilaiannya}

\section{A. Sikap memahami materi tugas individu}

\begin{tabular}{|c|l|}
\hline Nilai & \multicolumn{1}{|c|}{ Kecenderungan sikap yang muncul } \\
\hline 1 & Tidak faham dan tidak mau menanyakan ke dosen \\
2 & Tidak faham terhadap tugas namun mau menanyakan ke dosen \\
3 & Memahami materi tugas individu namun penyelesaiannya kurang sempurna \\
4 & Memahami tugas dan dapat menyelesaikan tugas sesuai dengan ketentuan \\
\hline
\end{tabular}

\section{B. Sikap bertanggungjawab terhadap tugas mencari materi perkuliahan}

\begin{tabular}{|c|l|}
\hline Nilai & \multicolumn{1}{|c|}{ Kecenderungan sikap yang muncul } \\
\hline 1 & Mau mencari materi tugas namun hanya sebagian saja \\
2 & Mau dan bisa mencari materi tugas secara garis besar \\
3 & Bisa merumuskan materi secara mandiri namun hasilnya kurang sempurna \\
4 & Bisa merumuskan materi tugas individu secara sempurna \\
\hline
\end{tabular}




\section{Sikap dalam penyelesaian tugas individu}

\begin{tabular}{|c|l|}
\hline Nilai & \multicolumn{1}{|c|}{ Kecenderungan sikap yang muncul } \\
\hline 1 & Menyelesaikan tugas individu namun kurang sempurna dan tidak tepat \\
& waktu \\
3 & Menyelesaikan tugas sudah sesuai dengan waktu namun kurang sempurna \\
4 & Menyelesaikan tugas individu sesuai dengan ketentuan tugas \\
& Menyelesaikan tugas individu dengan sempurna dan lebih awal dari jadwal \\
& yang ditentukan
\end{tabular}

\section{Sikap dalam mempresentasikan tugas individu}

\begin{tabular}{|c|c|}
\hline Nilai & Kecenderungan sikap yang muncul \\
\hline 1 & $\begin{array}{l}\text { Mau mempresentasikan hasil tetapi kurang sistematis dan tidak bisa } \\
\text { menyelesaikan permasalahan }\end{array}$ \\
\hline 2 & $\begin{array}{l}\text { Bisa mempresentasikan, tetapi belum bisa menyelesaikan masalah yang } \\
\text { muncul }\end{array}$ \\
\hline 3 & Bisa mempresentasikan hasil dan menjawab pertanyaan yang muncul \\
\hline 4 & $\begin{array}{l}\text { Bisa mempresentasikan dan menjawab dengan baik, bahkan dengan } \\
\text { memberikan contoh-contoh serta pengembangan materi. }\end{array}$ \\
\hline
\end{tabular}

Setelah data diperoleh kemudian penulis analisis menggunakan uji - t, untuk mengetahui efektivitas suatu tindakan pada satu group sampel, yaitu penerapan pembelajaran tugas individu terhadap kemampuan belajar mandiri pada Mahasiswa Baru PG-PAUD. 


\section{PEMBAHASAN}

Hasil penelitian yang diolah melalui analisa uji t sangat signifikan, yaitu:

$$
\begin{array}{ll}
\frac{4,6}{\sqrt{\frac{56,8}{20(20-1)}}} & t=\frac{4,6}{\sqrt{\frac{56,8}{380}}} \\
t=\frac{4,6}{\sqrt{0,15}} & t=11,80
\end{array}
$$

Diketahui :

Jumlah Responden $(\mathrm{N})=20$

$\mathrm{Db}=\mathrm{N}-1 \quad=19$

T hitung $\quad=11,80$

T tabel Signifikasi $5 \%=2,093$

Perbandingan hasil T-h \& T- $\mathrm{t}=$

$$
11,80>2,093
$$

Suatu rumus: Jika

signifikasinya uji $t_{\text {hitung }}$ lebih besar dari $t_{\text {tabel artinya ada pengaruh/ }}$ peranan. Jika signifikasinya $u j i t_{h i t u n g}$ lebih kecil dari $t_{\text {tabel }}$ artinya tidak ada pengaruh/peranan. Sesuai hasil analisis data dalam penelitian ini bahwa nilai $t_{\text {hitung }}$ lebih besar dari $\mathrm{t}_{\text {tabel }}$ dengan taraf signifikansi 5\% yaitu: $11.80>2.093$, maka hipotesa yang menyatakan "pembelajaran tugas individu terhadap kemandirian dalam belajar sebagai Mahasiswa Baru pada PG-PAUD Universitas PGRI Adi Buana Surabaya" diterima.

Selanjutnya hasil rekapan dari nilai pre tes dan pos tes dalam penelitian ini dapat ditabulasikan sebagai berikut: 
Tabel 1

Tabulasi hasil Pre-test dan Post-test

\begin{tabular}{|c|c|c|c|}
\hline Subjek & $\begin{array}{l}\text { Hasil Pre- } \\
\text { test }\end{array}$ & $\begin{array}{c}\text { Hasil Post- } \\
\text { Test }\end{array}$ & Peningkatan Skor \\
\hline 1 & 7 & 13 & 6 \\
\hline 2 & 10 & 14 & 4 \\
\hline 3 & 9 & 12 & 3 \\
\hline 4 & 9 & 13 & 4 \\
\hline 5 & 10 & 13 & 3 \\
\hline 6 & 10 & 15 & 5 \\
\hline 7 & 7 & 11 & 4 \\
\hline 8 & 9 & 16 & 7 \\
\hline 9 & 10 & 16 & 6 \\
\hline 10 & 10 & 15 & 5 \\
\hline 11 & 8 & 14 & 6 \\
\hline 12 & 10 & 15 & 5 \\
\hline 13 & 11 & 12 & 1 \\
\hline 14 & 5 & 14 & 9 \\
\hline 15 & 7 & 11 & 4 \\
\hline 16 & 9 & 12 & 3 \\
\hline 17 & 6 & 11 & 5 \\
\hline 18 & 7 & 12 & 5 \\
\hline 19 & 10 & 13 & 3 \\
\hline 20 & 11 & 15 & 4 \\
\hline Jumlah & 175 & 268 & 92 \\
\hline
\end{tabular}

Keterangan : Skor maksimal Pre tes/pos tes $=16$

Tabel : 2

Rekapan peningkatan hasil

\begin{tabular}{|c|c|c|}
\hline No. & $\begin{array}{c}\text { Peningkatan Skor dari nilai } \\
\text { pre tes ke post tes }\end{array}$ & Jml mahasiswa \\
\hline 1. & Tidak meningkat & 0 \\
\hline 2. & Meningkat $: 1-3$ poin & 5 \\
\hline 3. & Meningkat $: 4-6$ poin & 13 \\
\hline 4. & Meningkat $: 7-9$ poin & 2 \\
\hline 5. & Meningkat $: 10-12$ poin & 0 \\
\hline & Jumlah & 20 \\
\hline
\end{tabular}


Mayoritas mahasiswa setelah mendapat tugas pembelajaran individu dapat melakukan belajar secara mandiri. Pertama: Misalnya mencari bahan referensi: Dari 5 mahasiswa menjadi 18 mahasiswa yang sudah bisa melakukan pencarian materi perkuliahan. Mereka sudah bisa melakukan pencarian dan pengembangan materi perkuliahan dari media internet, dari referensi buku, maupun jurnal ilmiah. Mereka bila mempertahankan isi materi presentasi sudah bisa menunjukkan sumber materi yang digunakan. Disamping itu mereka juga bisa memberi ilustrasi saat menjelaskan hasil presentasi. Memang masih ada 2 mahasiswa yang harus diingatkan dan perlu bimbingan saat mencari dan mengembangkan isi materi perkuliahan. Mereka belum bisa menyimpulkan terhadap bahan yang sangat relevan sebagai materi perkuliahan. Kedua: Misalnya upaya memahami materi sendiri: Mayoritas (16 mahasiswa) bila mengalami kesulitas terhadap hasil referensi yang diperoleh, mereka selalu mendisuksikan dengan temannya, bahkan menanyakan kepada dosennya. Mereka sudah bisa menanyakan tentang kesulitan dalam memahami suatu materi. Disamping itu mereka juga aktif untuk mencatat atau merekam dari hasil konsultasi. Pada saat pre tes dilaksanakan, hanya 6 mahasiswa yang sudah bisa memahami materi perkuliahan dengan berupaya sendiri. Yaitu dengan jalan membaca referensi lain atau melalui internet. Selanjutnya untuk yang lain belum bisa mengekplore materi perkuliahan. Ketiga: Misalnya upaya mempertahankan dan mengklarifikasi materi secara mandiri saat berdiskusi dengan teman-temannya: Dari 8 mahasiswa menjadi 17 mahasiswa yang sudah bisa melakukan presentasi dengan baik. Mereka sudah bisa membuat power point dengan jelas, runtut dan menarik. Mereka sudah dapat menggunakan bahasa presentasi dengan jelas dan komunikatif. Mereka juga sudah bisa menjawab dan menerima masukan dari temantemannya. Memang masih ada 3 mahasiswa yang harus perlu ditingkatkan untuk belajar berpresentasi di hadapan temantemannya. Mereka masih memiliki sikap kurang percaya diri dan kurang menguasai materi. Misalnya pada saat menyajikan tayangan presentasi, mereka tidak mau melihat/berpandangan mata dengan peserta. Tidak memahami pertanyaan teman, serta tidak dapat menjawab dengan jelas. 
Pembahasan dari hasil penelitian ini bahwa tugas individu sangat efektif terhadap sikap kemandirian dalam belajar sebagai mahasiswa baru. Melalui pengetrapan tugas individual dalam perkuliahan membuat mayoritas mahasiswa mudah melakukan belajar secara mandiri, dan bisa merubah maind set dari model belajar pada saat di jenjang SLTA menjadi model belajar saat di Perguruan Tinggi. Hal ini terbukti pada saat mahasiswa berpresentasi hasil pelaksanaan tugas individual. Mereka bisa menemukan materi sendiri, mereka bisa memahami materi dengan berupaya secara mandiri, serta mereka dapat menyiapkan materi dan melaksanakan presentasi dengan jelas dan lancar.

\section{KESIMPULAN}

Berdasarkan hasil analisa data maka dapat diambil suatu kesimpulan sebagai berikut:

1. Tugas individu sangat efektif sebagai pengembangan kemampuan belajar mandiri untuk mahasiswa baru.

2. Perubahan mind set terhadap cara belajar bagi mahasiswa baru pada perguruan tinggi dapat dilakukan melalui pemberian tugas secara individual.

\section{DAFTAR PUSTAKA}

Angkoro, R., dan Kosasih, A. (2007). Optimalisasi Media Pembelajaran. Jakarta: Grasindo

Anitah, Sri, dkk. (2007). Strategi Pembelajaran di SD. Jakarta: Universitas Terbuka.

Arikunto, Suharsimi. (2006). Prosedur Penelitian Suatu Pendekatan Praktik (Edisi VI). Jakarta: Rineka Cipta.

Atwi, Suparman. (1997). Desain Instruksional: Program Pengembangan Keterampilan Dasar Teknik Instruksional (PEKERTI) Untuk Dosen Muda. Jakarta: Pusat Antar Universitas Untuk Peningkatan Dan Pengembangan Aktivitas Instruksional. Direktorat Jenderal Pendidikan Tinggi, Depdikbud.

Ibrahim, M., Fida R., Mohamad Nur dan Ismono. (2005). Pembelajaran Kooperatif. Surabaya: PSMS UNESA.
---------. (2005). Pembelajaran Berdasarkan Masalah. Surabaya: PSMS UNESA.

Kardi, S., dan M.Nur. (2004). Pembeajaran Langsung, Surabaya: PSMS UNESA.

Noorlaili, Iva. (2010). Panduan Lengkap Mengajar PAUD. Yogyakarta: Bookpublisher 
Rita Eka Izzaty S. (2005). Menggali

Permasalahan Perkembangan

Anak. Jakarta: Depdikbud, Dirjen Dikti.

Soekartawi, Suhardjono, T. Hartono dan A. Ansharullah. (1995). Meningkatkan Rangcangan Instruksional (instructional Design): Untuk Memperbaiki Kualitas Belajar Mengajar. Jakarta: Raja Grafinda Persada.

Sri Anitah, dkk. (2007). Strategi Pembelajaran di TK. Jakarta: Universitas Terbuka

Sudjana. N. (1989). Media Pengajaran. Bandung: CV Sinar baru

Sudono, Anggani. (2010). Sumber Belajar dan Alat Permainan untuk Pendidikan Anak Usia Dini. Jakarta: PT Grasindo

Undang Undang Nomor 20 tahun 2003. Tentang Sistem Pendidikan Nasional. Jakarta: Depdiknas. 